\title{
Examination of knowledge barriers in packaging industry using Interpretive Structural Modeling (ISM)
}

\author{
S. Bathrinath, Vadakapur Sai charan, M. Saravana Mohan, S. Saravanasankar
}

\begin{abstract}
The efficient running of any packaging plant makes the organization successful. To achieve the efficiency of the packaging plant we must control and overcome the barriers which make the plant ineffective according to the optimum efficiency. Packaging plays an important role in all of the history of the modern manufacturing whether it is past or in the future. Today industries seek to improve their packaging capability in all the possible ways in order to improve their position in the sector. This paper focuses on packaging industry on the selection and analysis of the barriers which are responsible for inefficiency of the packaging plant. Organizations find difficulties in identifying the barriers which are responsible for the efficiency of the production. So, this requires in depth analysis in selecting the barriers, analyzing the barriers and ranked them according to the power they possess in the packaging industry. We have identified eight barriers which are responsible for the inefficiency of the packaging plant and ranked them according to the power they possess on the packaging industry. We have applied Interpretive Structural Modeling (ISM) on eight barriers for the analysis. This study focuses on relating each barrier depending on the dependence power and driving power they possess on other barriers. This result helps the organization in overcoming the barriers and increase the effectiveness and efficiency of the packaging plant.
\end{abstract}

Keywords: Barriers, Interpretive structural modeling, manufacturing, Packaging.

\section{INTRODUCTION}

T he packaging industry is one of the key industry in the all the history of modern manufacturing whether it is in past or in the future [1]. The competition and the growth of the packaging industry is growing as time passes [2]. In this competitive environment, the packaging industries must improvise in the packaging plant production to be best out of the crowd. One of the method of improving the industry is to improve and overcome the barriers involved in the packaging industries [3-5]. There are many barriers which effects the productivity of the packaging plant. The packaging is the process of packing the product safe and with an aesthetic look. This helps the product to be shipped safe to the customer and also to

]Revised Manuscript Received on December 5, 2019

* Correspondence Author

S.Bathrinath*, Department of mechancical engineering, Kalasalingam Academy of research and education, Krishnankoil-626126, India. Email: bathri@gmail.com

Vadakapur Sai Charan, Department of mechancical engineering, Kalasalingam Academy of research and education, Krishnankoil-626126, India. Email: charanvadakapur@gmail.com

M.SaravanaMohan, Department of mechatronics engineering, Kumaraguru college of technology, Coimbatore, India. Email: saravana.moha@gmail.com

S.Saravanasankar, Department of mechancical engineering, Kalasalingam Academy of research and education, Krishnankoil-626126, India. Email: ssaravanasankar@klu.ac.in look good externally. In India packaging industry is one of the growing industries according to the future predictions. Now-a-days, the competition in the packaging industry has been increasing enormously due to the increase of e-commerce businesses and increase in long distance business opportunity. So, the packaging industry must compete with the competitors and improve the productivity in the industry [6]. In general, they are a lot of barriers which holds back the productivity of the packaging plants. In order to overcome the barriers, they have to identify the barriers responsible for the inefficiency of the plant and has to overcome the barriers to run the packaging plant efficiently.

The main focus on this paper is to identify the barriers involved in the packaging industries and rank them according to the influence they possess on each other. This helps the packaging industries in identifying the barriers and make decision on overcoming the barriers. Here the barriers are considered according to the literature review available on the packaging industries and the advice from the industrial experts. Here eight barriers are considered depending on the literature review and the advice from the industrial experts of the packaging industry. A proper packaging helps the company to elevate its position from the industries in the market. The proper packaging helps the product to be safe for the fragile materials. This all can only be achieving if the packaging industry provides a better solution and for the better solution the packaging industries must overcome the barriers which effects the efficiency of the packaging production. Packaging is the most crucial and important part of any industry because this is what makes the company recognized for their efficiency in the industry. According to Confederation of Indian Industry (CII) packaging is considered as one of the highly growing industry in India. These packaging industries not only solve the domestic requirements but also help the foreign trade business. Due to the high competitiveness in this sector, the companies are in need of new innovative practices in packaging and improving it in any possible manner.

There are so many barriers impacting the effective manufacturing which may affect the production of the plant. This study helps the packaging industries in identifying the barriers that affects the packaging industry and rank them according to the power they have on influencing the barriers. We have identified 8 barriers which effect the manufacturing and analyzed them according to the ranking of the barriers we have used interpretive structural modeling (ISM). This is a ranking methodology which helps the problem to be analyzed depending on the driving power and dependence power they possess on the barriers. Interpretive structural modeling is used for identifying and summarizing relationship among specific variables which defines the barriers involved in the packaging industries. This research helps the packaging industries to understand the barriers which affect the productivity and efficiency of the packaging industries.

\section{LITERATURE REVIEW}

The literatures available on packaging industry and Interpretive structural modeling, barriers affecting the packaging industries, methodology used by early researchers on packaging and other industries are reviewed in this section. 
The research gap on packaging industry is also discussed in this section. The interpretive structural modeling has been suggested by many researchers for identifying and summarizing relationship among specific variables [7]. Interpretive structural modeling has wide application in many industries like hospitals, supply chain managements, risk of failure etc. [8]. This interpretive structural modeling helps to rank the barriers or criteria according to the dependence power where the one criterion is influenced by other criteria [9]. In this research we have identified eight main barriers which effects productivity of the packaging industry. Here the criteria are the barriers that affect the packaging industry. There are many methodologies available for the ranking and for the optimization of the criteria [10-12]. Like, DEMATEL is an acceptable method to solve criteria involved incorporation of indirect relations in to compressed cause and effect method [13]. Ontology based action planning and verification, is the study based on the study of the domain or area of the properties and relationship between different criteria. The reason for the selection of interpretive structural modeling is because of its inter-relationship between the criteria selected [14].

Generally, it would be complex while planning and processing of any packaging industries [15]. There have been many research studies based on the packaging industry [16] but industries still seek new improvements in the packaging and also including overcoming of the barriers to have high production in the packaging industry [17]. There are many barriers which effects the packaging of any product. These barriers are considered after studying all the related literature available. We have considered eight barriers: lack of integration of IT systems (B1), lack of technical support (B2), unrealistic expectation of employee (B3), lack of compatibility between diverse IT systems (B4), mismatch between individuals this research are presented in Table 1 .

\section{METHODOLOGY}

Interpretive Structural Modeling is the methodology in finding the interrelationship among the barriers $[18,19]$. The knowledge management barriers will be analyzed with the ISM methodology, which will predict the interrelationships of the knowledge management routines and their various levels. For this analysis three classes of experts were identified in a manufacturing industry from the top, middle and low level. ISM presents the following eight steps [20].

Step 1: The factors affecting the system under circumstance are listed, which can be barriers, drivers, factors, criteria, objectives etc. Step 2: From the factors identified in step 1, a contextual interrelationship is framed among factors in relation with pairs of factors would be examined.

For analyzing the knowledge barriers in developing Structural Self Interaction Matrix (SSIM), the following four text symbols have been used to represent the direction of interrelationship between two knowledgebarriers $(i, j)$ :

$\mathrm{V}$ knowledge barriers i creates some influence knowledge barriersj

A knowledge barriers $\mathrm{j}$ creates some influence influences knowledgebarriersi

$\mathrm{X}$ knowledge barriers $\mathrm{i}$ and $\mathrm{j}$ creates some influence on each other

$\mathrm{O}$ knowledge barriers $\mathrm{i}$ and $\mathrm{j}$ do not creates any influence on each other.

Step 3: A SSIM is formulated for factors, which indicates pair wise interrelationships among factors of the system under circumstance.

The SSIM is changed into a binary matrix, called the initial reachability matrix by substituting $\mathrm{V}, \mathrm{A}, \mathrm{X}$ and $\mathrm{O}$ by one and zero as per the rules. The replacement of ones and zeroes are as per the following guidelines:(i) if the $(i, j)$ value in the SSIM is denoted as $\mathrm{V}$, the $(i, j)$ value in the reachability matrix will be considered as 1 and the $(j, i)$ (B5), reluctance to use IT system (B6), lack of training regarding employee familiarization (B7), lack of communication and demonstration (B8). The details about each barrier considered in

value will be considered as 0 , (ii) if the $(i, j)$ value in the SSIM is denoted as $\mathrm{A}$, the $(i, j)$ value in the reachability matrix will be considered as 0 and the $(j, i)$ entry will be considered as 1 , (iii) if the $(i, j)$ value in the SSIM is denoted as X, the $(i, j)$ value in the reachability matrix will be considered as 1 and the $(j, i)$ value also will be considered as 1 , (iv) if the $(i, j)$ value in the SSIM is denoted as $\mathrm{O}$, the $(i, j)$ entry in the reachability matrix will be considered as 0 and the $(j, i)$ value also will be considered as 0 . Step 4: A reachability matrix is formulated from SSIM and the matrix is analyzed for checking its transitivity. The transitivity of the contextual interrelation is a primary assumption followed in ISM. It indicates that if a considered barrier $\mathrm{A}$ is related to considered barrier B and B is related to considered barrier C, then A is certainly relatedtoC.

Step 5: The reachability matrix derived in Step 4 is split into various hierarchy

levels.

Step 6: The oriented graphical representation is presented by considering the interrelationships obtained from the reachability matrix and then transitivity barriers and its relevant links are removed.

Step 7: The subsequent digraph is changed into an ISM model, by replacing barriers.

Step 8: The newly generated ISM model formulated in Step 7 is analyzed for checking theoretical inconsistency and necessary changes are completed.

\section{IDENTIFICATION AND EVALUATION OF BARRIERS}

Form the literatures available on the packaging industry and from the advice of the industrial experts the eight barriers are selected. These industrial experts have high experience in the packaging industry for the decades. For the self-interactive matrix (Table 2), the industrial experts are asked to give their opinion on each barrier on other depending on the influencing factor. From this self-interactive matrix, the values are changed into binary code as per the methodology to get the initial reachability matrix (Table 3). A final reachability matrix (Table 4 ) has been formulated according to the methodology of the interpretive structural modeling. The driving power and the driven power has been calculated and a graph (Figure 1) is obtained with the help of dependence power and driving power. According to the methodology the iteration on the barriers has been performed.

\section{RESULT AND DISCUSSIONS}

Following the methodology of the interpretive structural modeling, we get the final reachability matrix. Also following the procedure of iteration of the barriers, we get to the level of 4 iterations where these results are used to find the hierarchy of the barriers. In this hierarchy, the criteria are ranked according to relative status with respect to the other barriers. In this section of the paper we are elaborating the results obtained in this study. From the final reachability matrix, we obtain with the results of dependence power and driving power of each barrier that we selected. From the matrix it is observed that B1(Lack of integration of IT systems), B2(Lack of technical supports), B3(unrealistic expectations of employee) and B6(reluctance to use IT systems) are having the high dependence power when compared with the other barriers. This shows that B1, B2, B3 and B6 are the barriers which are highly affected by other barriers. These barriers are highly depending on other barriers. B4 (Lack of compatibility between diverse IT systems) arrives to be the dependence power of 7 , which shows that it is the next highly depending barrier from the rest of the barriers. B5 (Mismatch between industries), B7(Lack of training regarding employee familiarization) and B8 (Lack of communication and demonstration) are the barriers which are having the least depending power from all the barriers. 
If we consider the driving power of the barriers, B8 (Lack of communication and demonstration) is having the highest driving power with the value of 8 . Here we can observe that this barrier is having the least dependence power with the value of 1 and highest driving power with the value 8 . This shows that this barrier B8 is the main influencing barriers than the rest of other barriers. Also, for the industries to work effectively and to reduce the barriers that affect the productivity of the plant, the main barrier that has to be considered is the B8 i.e. Lack of communication and demonstration. Also, the next barrier with high driving power is B7 (lack of training regarding employee familiarization) with the driving power 7 . As compared to the B8; B7 is the next barrier which is having high driving power. The dependence power of the B7 is 2 . As seen in the B8; B7 also have the low dependence power and high driving power. Lack of training is also one of the key influencing factors in the total barriers. B4, B5 and B6 are next barriers with the driving power of 5 . And the least driving power is obtained with the B1, B2 and B3. By using the information obtained from the final reachability matrix, a graph has been plotted with the variables as dependence power and the driving power.

\section{Dependence vs Driving Graph}

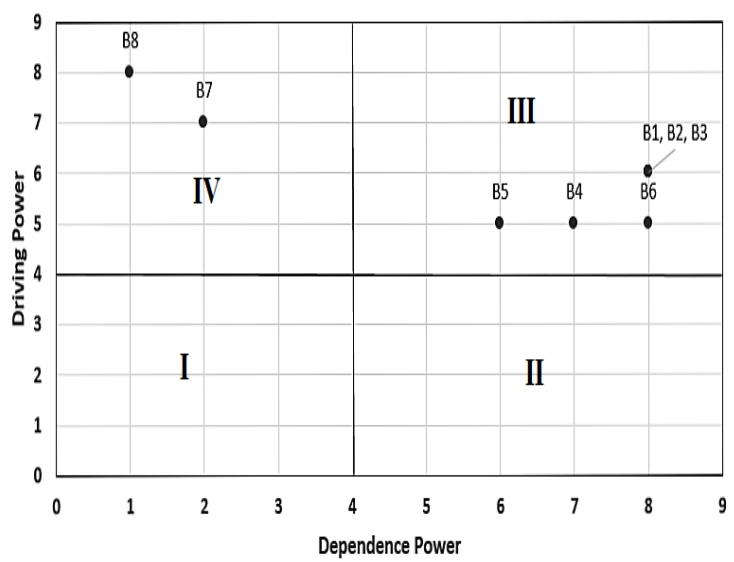

Fig. 1. Dependence vs. Driving power

The graph is divided in to four sub - coordinate system namely, quadrant I, quadrant II, quadrant III and quadrant IV. The region in the quadrant I is said to have less dependence power as well as less driving power. In the quadrant II the area represents high dependence power and less driving power. In the quadrant III the area represents high dependence power as well as high driving power. And in the quadrant IV the area represents the barriers with low dependence power and high driving power. This graph is used to get the accurate information about which barrier is influencing other barrier. Here we can observe that the barriers are only designated in the quadrant IV and quadrant III. As discussed earlier the barriers which are under the quadrant III have high dependence as well as high driving power. The barriers B1, B2, B3, B4, B5 and B6 fall under the quadrant III region of the graph. These values are having the high dependence as well as high driving power. Also from the quadrant III it is observed that barriers B1, B2 and B3 are having the same values for dependence and driving power. The barriers which are under the quadrant IV are B7 and B8, these barriers are having high driving power and less dependence. If we rank the barriers depending on the dependence power, then the series look like this, $(\mathrm{B} 1, \mathrm{~B} 2, \mathrm{~B} 3$ and $\mathrm{B} 6)>\mathrm{B} 4>\mathrm{B} 5>\mathrm{B} 7>\mathrm{B} 8$. This shows that the $\mathrm{B} 1, \mathrm{~B} 2, \mathrm{~B} 3$ and $\mathrm{B} 6$ are the barriers which are depended by the other barriers. If we consider the ranking of the driving power, then the series look like $\mathrm{B} 8>\mathrm{B} 7>(\mathrm{B} 1, \mathrm{~B} 2$ and $\mathrm{B} 3)>$ (B5, B4, B6). Here we can observe that B8 is having the highest driving power which implies that this barrier is one which is driving all the barriers. From the graphs and the results obtained from the final reachability matrix, the iteration is performed on the values of barriers based on the methodology of interpretive structural modeling. The iteration is followed by four stage iteration processes in which, from each stage the barriers are eliminated and selected barriers are sent to the next level of iteration. The iteration is continued until we reach the final iteration stages where there are only barriers with same antecedent sets are available. The final barriers which are at highest level are the barriers with highest driving power. The hierarchical level of barriers depending on the interpretive structural modeling is shown in the flow chat represented in the figure (Fig. 2). This shows which barriers are influenced by other barriers.

From the results we can observe that the most influencing barrier when compared to all the other barriers is the B8 (Lack of communication and demonstration). Lack of communication and demonstration is the most important barrier that has been observed in the industry which is one of the factors in decreasing the efficiency of the packaging industry. Next important barrier is the B7 (Lack of training regarding employee familiarization), this barrier is influenced by the B8 and this barrier is influencing other barriers in the group. Lack of training to the employee is the major factor because the employee finds difficult in understanding the mechanism of the organization and understanding the work flow of the organization which influences on the efficiency of the packaging plant of the organization. Next barrier which is also the important barrier is B5 (Mismatch between individual). Here this barrier is influenced by B8 and B7. And this barrier is influencing the other rest of the barriers in the group. The communication gap between the individuals and mismatch of ideas between the individual is one of the important barriers in the industries which makes the organization run inefficiently. The rest of the barrier i.e. B1, B2, B3, B4 \& B6 are the barriers which are influenced by the barriers as discussed. So, for any packaging industry to run efficiently and to be successful in its domain the most important barriers to be considered is B8 i.e. lack of communication and demonstration.

\section{MANAGERIAL IMPLICATION}

The results obtained from the analysis of barriers in packing industries shows that lack of communication and demonstration plays an important role in the efficient working of the industry. The results obtained from the interpretive structural modeling are useful for the packaging industry to improve itself in the industry to avoid the barriers that are affecting the packaging industry. This research is helpful for the packaging industry in finding the most important barriers that affect the efficiency of the packaging industry. The ranking of the barriers helps the packaging industry in prioritizing the barriers and improve them in the packaging industry. The results show that the lacking of communication and demonstration with the different level of management in the industry is the most important barrier that needs to be improved in the packaging industry to help in improving the efficiency of the packaging industry. So, if any packaging industry is seeking for the improvement lack of communication and demonstration must to avoid achieving the efficiency. This research helps the packaging industry in improving or increasing the efficiency of the packaging industry.

\section{CONCLUSION}

The barriers are the most common problem that are faced by the packaging industries which makes the production of the plant ineffective and inefficient when compared to the full working potential of the production unit. The analysis of the barriers in the packaging industries using the interpretive structural modeling methodology has not been attempted in any of the literature provided to the best of our knowledge. This study is mainly focused on the barriers that are affecting the efficiency of the packaging industry. This helps in providing the information about the barriers involved in the packaging industries. Also, this helps to rank the barriers and prioritize the barriers depending on the influence of the barrier on other barriers. 
As discussed in the results section, the most effecting barrier from all the barriers selected is the lack of communication and demonstration. This barrier has the most driving power and less depending power when compared to the other barriers. If this barrier is solved, then the rest of the barriers can be overcome easily and effectively. This research helps the packaging industry in prioritizing the barriers that affect the efficiency of the production department. If we check the limitation of this research, since it addresses only eight barriers which are selected from the literature study and the advice from the industrial experts. But in the real life situation there might be many barriers which affect the packaging industry. These barriers are only based on the packaging industry so; these are not applicable for any other industries. Also, there is a lot of scope for this research in packaging industry like the supply chain management, customer services, machine durability and so on. Finally, this research helps the packaging industry in identifying the barrier that is mostly affecting the efficiency of the production department of the plant.

\section{REFERENCES}

1. E. Hofmann and A. Locker, "Value-based performance measurement in supply chains: a case study from the packaging industry," Production Planning and Control, Vol. 20(1), 2009, 68-81.

2. B. Rundh, "The multi-faceted dimension of packaging: marketing logistic or marketing tool?,” British food journal, Vol. 107(9), 2005 , 670-684.

3. A. M. Harris and E. C. Lee, "Improving mechanical performance of injection molded PLA by controlling crystallinity," Journal of applied polymer science, Vol. 107(4), 2008, 2246-2255.

4. D. Restuccia, U. G. Spizzirri, O. I. Parisi, G. Cirillo, M. Curcio, F. Iemma and N. Picci, "New EU regulation aspects and global market of active and intelligent packaging for food industry applications," Food Control, Vol. 21(11), 2010, 1425-1435.

5. M. Cushen, J. Kerry, M. Morris, M. Cruz-Romero and E. Cummins, "Nanotechnologies in the food industry-Recent developments, risks and regulation," Trends in Food Science \& Technology, Vol. 24(1), 2012, $30-46$.

6. P. L. Chang and C. T. Tsai, "Finding the niche position - competition strategy of Taiwan's IC design industry," Technovation, Vol. 22(2), 2002, 101-111.

7. M. D. Singh and R. Kant, R. "Knowledge management barriers: An interpretive structural modeling approach," International Journal of Management Science and Engineering Management, Vol. 3(2), 2008, 141-150.

8. D. W. Malone, "An introduction to the application of interpretive structural modeling," Proceedings of the IEEE, Vol. 63(3), 1975, 397-404.

9. K. Govindan, M. Palaniappan, Q. Zhu and D. Kannan, "Analysis of third party reverse logistics provider using interpretive structural modeling," International Journal of Production Economics, Vol. 140(1), 2012, 204-211.

10. K. E. Parsopoulos and M. N. Vrahatis, "Particle swarm optimization method in multiobjective problems," In Proceedings of the 2002 ACM symposium on Applied computing, 2002, pp. 603-607, ACM.

11. A. Fischer, "A special Newton-type optimization method," Optimization, Vol. 24(3-4), 2002, 269-284.

12. K. S. Lee and Z. W. Geem, "A new structural optimization method based on the harmony search algorithm," Computers \& structures, Vol. 82(9-10), 2004, 781-798.

13. J. I. Shieh, H. H. Wu and K. K. Huang, "A DEMATEL method in identifying key success factors of hospital service quality," Knowledge-Based Systems, Vol. 23(3), 2010, 277-282.

14. R. H. Watson, "Interpretive structural modeling-A useful tool for technology assessment?," Technological Forecasting and Social Change, Vol. 11(2), 1978, 165-185.

15. S. Young, "Breaking down the barriers to packaging innovation," Design Management Review, Vol. 15(1), 2004, 68-73.

16. C. Barnes, T. Childs, B. Henson and S. Lillford, "Kansei engineering toolkit for the packaging industry," The TQM Journal, Vol. 20(4), 2008, 372-388.

17. R. J., Eller and J. J. Cardillo, "U.S. Patent No. 7,225,040. Washington, DC: U.S. Patent and Trademark Office," 2007.

18. J. N. Warfield, "Developing subsystem matrices in structural modeling," IEEE Transactions on Systems, Man, and Cybernetics, Vol. (1), 1974, 74-80.
19. A. Sage, Interpretive structural modeling: methodology for large-scale systems, 1974, 91-164.

20. V. Ravi and R. Shankar, "Analysis of interactions among the barriers of reverse logistics," Technological Forecasting and Social Change, Vol. 72(8), 2004, 1011-1029.

21. I. Nonaka, P. Reinmoller and R. Toyama, "Integrated information technology systems for knowledge creation," Handbook of organizational learning and knowledge, 2001, 827-848.

22. A. Das, "Knowledge and productivity in technical support work," Management Science, Vol. 49(4), 2003, 416-431.

23. P. M. Podsakoff, S. B. MacKenzie and W. H. Bommer, "Transformational leader behaviors and substitutes for leadership as determinants of employee satisfaction, commitment, trust, and organizational citizenship behaviors," Journal of management, Vol 22(2), 2006, 259-298

24. G. Mason, "The labour market for engineering, science and IT graduates: are there mismatches between supply and demand? DfEE,' 2009 ,

25. J. A. Senn, "Information technology in business: principles, practices, and opportunities," Prentice Hall PTR, 2007.

26. M. J. Bitner, "Evaluating service encounters: the effects of physical surroundings and employee responses," the Journal of Marketing, 1996 , 69-82.

27. E. M. Rogers and F. F. Shoemaker, "Communication of Innovations; A Cross-Cultural Approach,” 1971.

\section{AUTHORS PROFILE}

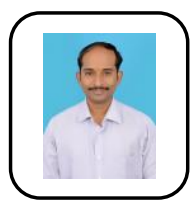

Dr.S.Bathrinath is an Associate Professor in the Department of Mechanical Engineering, Kalasalingam Academy of Research and Education, Krishnankoil, Tamilnadu, India. His current area of research includes multi-criteria decision making, scheduling \& optimization, soft computing and Artificial intelligence. He has published a number of papers in journal of national/international repute and presented a number of papers in various conferences/symposia in India and abroad. He is presently guiding a number of master/doctoral research scholars. Dr.S.Bathrinath is the corresponding author and can be contacted at: bathri@gmail.com

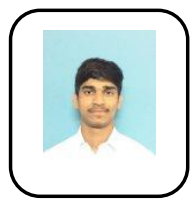

Vadakapur Sai Charan is currently doing final year B.E(MECH) in kalasalingam academy of research and education, Krishankovil,,Tamilnadu,India.

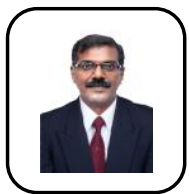

Dr.M. Saravana Mohan received his B.E., M.E., and $\mathrm{PhD}$ degrees in 1997, 2001 and 2017 from Madurai-Kamaraj University, MIT Chennai, Anna University respectively. He has also completed certificate course in SAP- ERP(SD Module) in Pricol Academy Coimbatore in 2006. He has seventeen years of teaching experience in various Indian institutions. He specializes in Mechatronics and doctorate in Robotics. He is an active designer in automation and received IVCA innovator award in I3 National Level competition organised by IIT -AICTE, Delhi in 2014. . He is involved in DRDO and AICTE sponsored projects on underwater robotics as a Co-investigator. He is currently working as an Associate Professor in Kumaraguru College of Technology, Coimbatore, India.

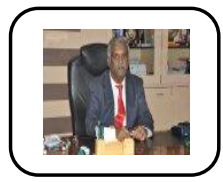

Dr.S.Saravanasankar is a Senior Professor in the Department of Mechanical Engineering, Kalasalingam Academy of Research and Education, Krishnankoil, Tamilnadu, India. He has more than 20 years of experience in teaching and research. His current area of research includes scheduling, optimization and multi-criteria decision making. He has published more than 40 research articles in journals of national and international repute. 
Table- I: Barriers included in the analysis

\begin{tabular}{|c|c|c|c|}
\hline $\begin{array}{c}\text { S. } \\
\text { no. }\end{array}$ & $\begin{array}{c}\text { Detonatio } \\
\text { n }\end{array}$ & Barriers & $\begin{array}{c}\text { Referenc } \\
\text { e }\end{array}$ \\
\hline 1. & B1 & Lack of integration of IT systems & {$[21]$} \\
\hline 2. & B2 & Lack of technical support & {$[22]$} \\
\hline 3. & B3 & Unrealistic expectation of employee & {$[23]$} \\
\hline 4. & B4 & $\begin{array}{c}\text { Lack of compatibility between diverse } \\
\text { IT systems }\end{array}$ & {$[24]$} \\
\hline 5. & B5 & Mismatch between individuals & {$[25]$} \\
\hline 6. & B6 & Reluctance to use IT systems & {$[26]$} \\
\hline 7. & B7 & $\begin{array}{c}\text { Lack of training regarding employee } \\
\text { familiarization }\end{array}$ & {$[27]$} \\
\hline 8. & B8 & $\begin{array}{c}\text { Lack of communication and } \\
\text { demonstration }\end{array}$ & {$[28]$} \\
\hline
\end{tabular}

Table- II: Self-interactive matrix

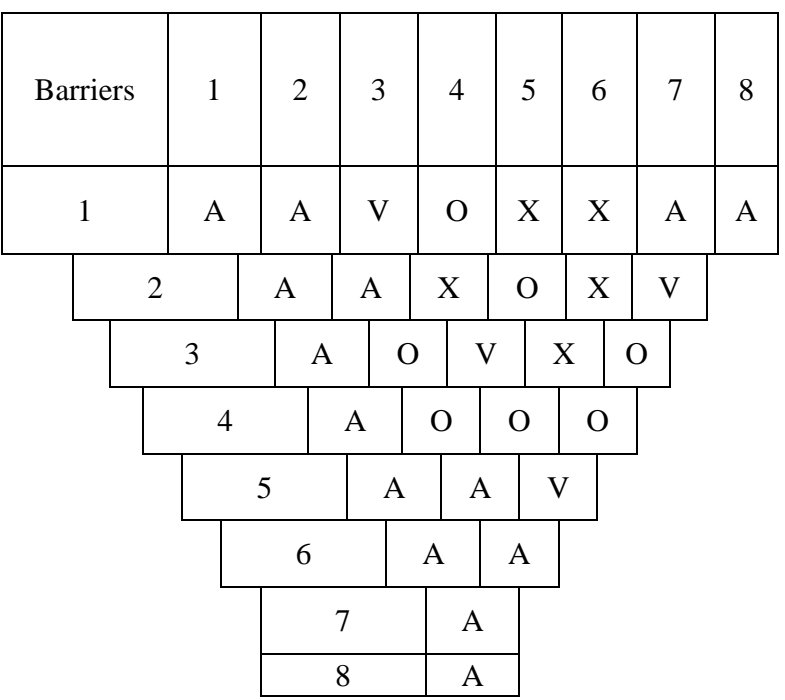

Table- III: Initial reachability matrix

\begin{tabular}{|c|c|c|c|c|c|c|c|c|}
\hline Barriers & 1 & 2 & 3 & 4 & 5 & 6 & 7 & 8 \\
\hline 1 & 1 & 0 & 1 & 1 & 0 & 1 & 0 & 0 \\
\hline 2 & 1 & 1 & 1 & 1 & 0 & 1 & 0 & 0 \\
\hline 3 & 1 & 0 & 1 & 0 & 1 & 1 & 0 & 0 \\
\hline 4 & 1 & 1 & 0 & 1 & 0 & 0 & 0 & 0 \\
\hline 5 & 0 & 0 & 1 & 0 & 1 & 1 & 0 & 0 \\
\hline 6 & 0 & 1 & 0 & 0 & 0 & 1 & 0 & 0 \\
\hline 7 & 1 & 1 & 0 & 0 & 1 & 1 & 1 & 0 \\
\hline 8 & 1 & 1 & 1 & 1 & 1 & 1 & 1 & 1 \\
\hline
\end{tabular}

Table- IV: Final reachability matrix

\begin{tabular}{|c|c|c|c|c|c|c|c|c|c|}
\hline Enablers & 1 & 2 & 3 & 4 & 5 & 6 & 7 & 8 & $\begin{array}{c}\text { Driving } \\
\text { Power }\end{array}$ \\
\hline 1 & 1 & 1 & 1 & 1 & 1 & 1 & 0 & 0 & 6 \\
\hline 2 & 1 & 1 & 1 & 1 & 1 & 1 & 0 & 0 & 6 \\
\hline 3 & 1 & 1 & 1 & 1 & 1 & 1 & 0 & 0 & 6 \\
\hline 4 & 1 & 1 & 1 & 1 & 0 & 1 & 0 & 0 & 5 \\
\hline 5 & 1 & 1 & 1 & 0 & 1 & 1 & 0 & 0 & 5 \\
\hline 6 & 1 & 1 & 1 & 1 & 0 & 1 & 0 & 0 & 5 \\
\hline
\end{tabular}

\begin{tabular}{|c|c|c|c|c|c|c|c|c|c|}
\hline 7 & 1 & 1 & 1 & 1 & 1 & 1 & 1 & 0 & 7 \\
\hline 8 & 1 & 1 & 1 & 1 & 1 & 1 & 1 & 1 & 8 \\
\hline $\begin{array}{c}\text { Dependence } \\
\text { power }\end{array}$ & 8 & 8 & 8 & 7 & 6 & 8 & 2 & 1 & \\
\hline
\end{tabular}

Table- V: Iteration 1

\begin{tabular}{|c|c|c|c|c|}
\hline Barriers & $\begin{array}{c}\text { Reachability } \\
\text { Set }\end{array}$ & Antecedent Set & $\begin{array}{c}\text { Intersection } \\
\text { Set }\end{array}$ & Level \\
\hline 1 & 123456 & 12345678 & 123456 & I \\
\hline 2 & 123456 & 12345678 & 123456 & I \\
\hline 3 & 123456 & 12345678 & 123456 & I \\
\hline 4 & 12346 & 1234678 & 12346 & I \\
\hline 5 & 12356 & 123578 & 1235 & \\
\hline 6 & 12346 & 12345678 & 12346 & I \\
\hline 7 & 1234567 & 78 & 7 & \\
\hline 8 & 1234567 & 8 & 8 & \\
\hline
\end{tabular}

Table- VI: Iteration 2

\begin{tabular}{|c|c|c|c|c|}
\hline Barriers & $\begin{array}{c}\text { Reachability } \\
\text { Set }\end{array}$ & $\begin{array}{c}\text { Antecedent } \\
\text { Set }\end{array}$ & Intersection Set & Level \\
\hline 5 & 12356 & 123578 & 1235 & II \\
\hline 7 & 1234567 & 78 & 7 & \\
\hline 8 & 12345678 & 8 & 8 & \\
\hline
\end{tabular}

Table- VII. Iteration 3

\begin{tabular}{|c|c|c|c|c|}
\hline Barriers & $\begin{array}{c}\text { Reachability } \\
\text { Set }\end{array}$ & Antecedent Set & $\begin{array}{c}\text { Intersection } \\
\text { Set }\end{array}$ & Level \\
\hline 7 & 57 & 78 & 7 & III \\
\hline 8 & 578 & 8 & 8 & \\
\hline
\end{tabular}

Table- VIII. Iteration 4

\begin{tabular}{|c|c|c|c|c|}
\hline Barriers & $\begin{array}{c}\text { Reachability } \\
\text { Set }\end{array}$ & $\begin{array}{c}\text { Antecedent } \\
\text { Set }\end{array}$ & $\begin{array}{c}\text { Intersection } \\
\text { Set }\end{array}$ & Level \\
\hline 8 & 78 & 8 & 8 & IV \\
\hline
\end{tabular}

Published By:

Blue Eyes Intelligence Engineering \& Sciences Publication 


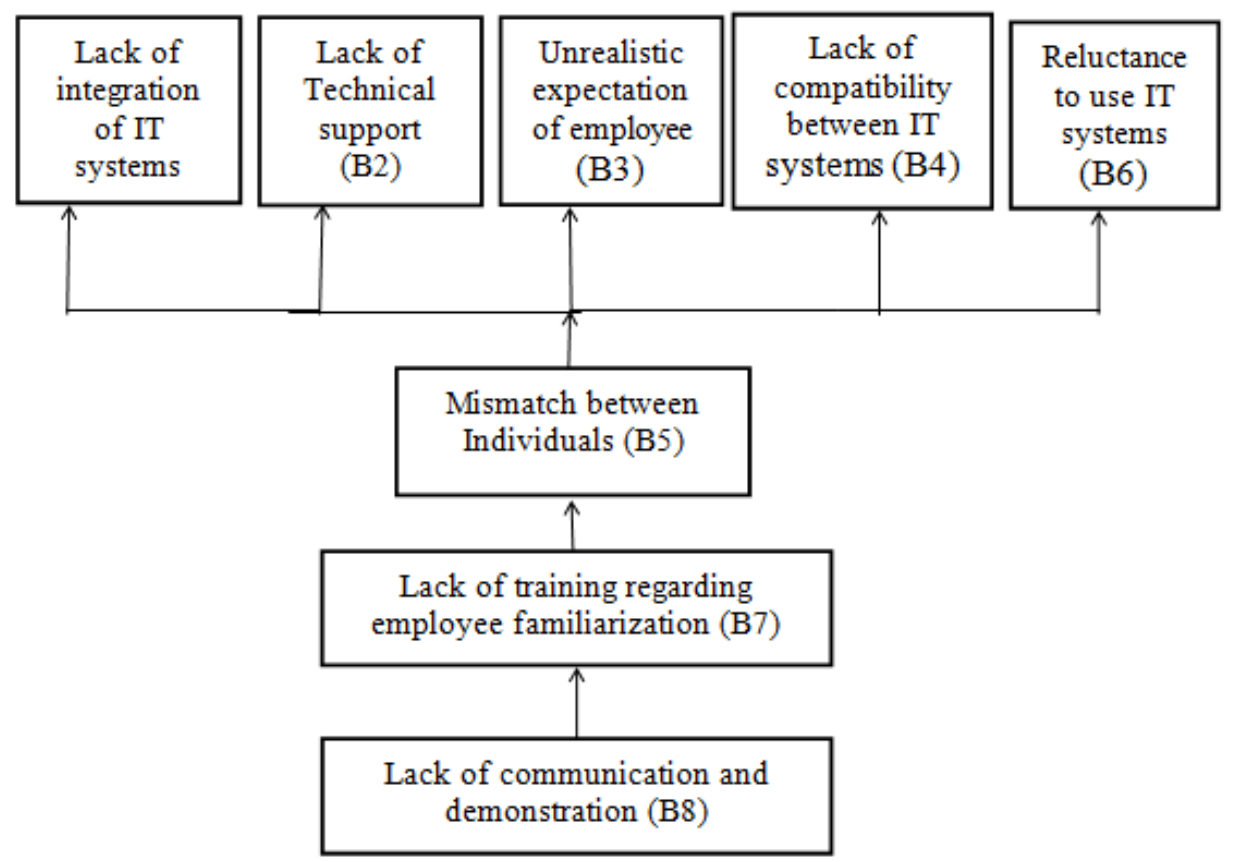

Fig. 2. Levels of ISM methodology 